\title{
Incentive spirometry in major surgeries: a systematic review
}

\author{
Incentivador respiratório em cirurgias de grande porte: uma revisão sistemática
}

\author{
Celso R. F. Carvalho, Denise M. Paisani, Adriana C. Lunardi
}

\begin{abstract}
Objective: To conduct a systematic review to evaluate the evidence of the use of incentive spirometry (IS) for the prevention of postoperative pulmonary complications and for the recovery of pulmonary function in patients undergoing abdominal, cardiac and thoracic surgeries. Methods: Searches were performed in the following databases: Medline, Embase, Web of Science, PEDro and Scopus to select randomized controlled trials in which IS was used in the pre- and/or post-operative period in order to prevent postoperative pulmonary complications and/or recover lung function after abdominal, cardiac and thoracic surgery. Two reviewers independently assessed all studies. In addition, the study quality was assessed using the PEDro scale. Results: Thirty studies were included (14 abdominal, 13 cardiac and 3 thoracic surgery; $n=3,370$ patients). In the analysis of the methodological quality, studies achieved a PEDro average score of 5.6, 4.7 and 4.8 points in abdominal, cardiac and thoracic surgeries, respectively. Five studies (3 abdominal, 1 cardiac and 1 thoracic surgery) compared the effect of the IS with a control group (no intervention) and no difference was detected in the evaluated outcomes. Conclusion: There was no evidence to support the use of incentive spirometry in the management of surgical patients. Despite this, the use of incentive spirometry remains widely used without standardization in clinical practice.
\end{abstract}

Keywords: incentive spirometry; surgery; postoperative care; postoperative complication; physical therapy; breathing exercise.

\section{Resumo}

Objetivo: Realizar um levantamento da literatura para avaliar as evidências do uso do incentivador respiratório (IR) na prevenção de complicações pulmonares pós-operatórias (CPPs) e recuperação da função pulmonar em pacientes submetidos a cirurgias abdominal, cardíaca e torácica. Métodos: Esta revisão sistemática utilizou as bases de dados Medline, Embase, Web of Science, PEDro e Scopus para selecionar ensaios clínicos randomizados, nos quais o IR foi utilizado nos período pré e/ou pós-operatório, visando prevenir CPP e/ou recuperar função pulmonar após cirurgias abdominal, cardíaca ou torácica. Dois revisores analisaram independentemente os estudos. Além disso, a qualidade dos estudos foi avaliada segundo a escala PEDro. Resultados: Trinta estudos foram incluídos (14 de cirurgia abdominal, 13 de cardíaca e três de torácica; $n=3370$ pacientes). Na análise de qualidade, os estudos obtiveram média de 5,6, 4,7 e 4,8 pontos nas cirurgias abdominais, cardíacas e torácicas, respectivamente. Cinco estudos (três de cirurgia abdominal, um de cardíaca e um de torácica) compararam o efeito do IR com grupo controle (sem intervenção) e não se verificou diferença nos desfechos estudados. Conclusão: Não se encontraram evidências que subsidiem o uso do IR no manejo de pacientes cirúrgicos. Apesar disso, o uso do IR continua não-padronizado e amplamente difundido na prática clínica.

Palavras-chave: incentivador respiratório; cirurgia; cuidado pós-operatório; complicação pós-operatória; fisioterapia; exercício respiratório.

Received: 06/07/2011 - Revised: 06/28/2011 - Accepted: 06/30/2011 


\section{Introduction $: \because$.}

Postoperative pulmonary complications (PPC) present high rates of morbidity, mortality, increased hospital costs and prolonged hospital stay predominantly in abdominal, cardiac and thoracic surgery ${ }^{1-3}$. The incidence of PPC varies according to the previous diagnosis of the candidates for surgery; the type of surgery and the definition of $\mathrm{PPC}^{4}$. For all these reasons, the incidence rates vary dramatically, ranging from 2 to $40 \%^{4-6}$. Atelectasis, pneumonia, tracheobronchitis, bronchospasm, exacerbation of chronic obstructive pulmonary disease, acute respiratory failure and prolonged mechanical ventilation (longer than 48 hours) can be classified as PPCs ${ }^{1,7,8}$. However, most of the studies have considered as PPCs those conditions that present clinical repercussions, such as pneumonia and acute respiratory failure, as they increase postoperative morbidity and mortality ${ }^{9-11}$. The major causes of PPCs may be related to shallow breathing and monotonous tidal volume in post-operative patients ${ }^{12}$. However, other causes such as anesthesia, opioid analgesia, and postoperative pain also seem to contribute to this ventilation pattern without spontaneous deep breaths that occurs every 5 or 10 minutes $^{13}$.

As a result, physical therapy techniques of lung re-expansion have been recommended as strategies to prevent and/or to treat the PPCs, as well as to recover the ventilatory function in the postoperative period ${ }^{1,4,14,15}$. Techniques such as deep inspiration (DI), incentive spirometry (IS) and positive airway pressure exercises stimulate the generation of a large and sustained increase in the transpulmonary pressure, with consequent expansion of collapsed alveolar units in order to prevent and/or to treat the PPCs ${ }^{16}$. The IS has been widely used in clinical practice ${ }^{17}$, especially in the management of patients in the pre and post-operative period of major surgeries ${ }^{8}$, due to its low cost, ease of application and good adherence of patients to the method ${ }^{18}$.

On the other hand, the evidence supporting the use of such equipment to reduce postoperative pulmonary complications is not yet established, and there are controversies about the effectiveness in the prevention and/or in the treatment of PPCs in abdominal ${ }^{19,20}$, cardiac $^{21}$ and thoracic ${ }^{22}$ surgery. Systematic reviews on this topic have been published previously ${ }^{19-22}$, however, this review updates the evidence in this field to establish the efficacy of IS in the prevention of PPCs in the early recovery of lung volumes and also in the reduction of hospital stay after abdominal, cardiac and thoracic surgery.

Therefore, the objective of this study was to conduct a systematic review to evaluate the quality of the evidence on use of IS in the prevention of PPCs and in the recovery of pulmonary function in patients undergoing cardiac, thoracic and/or abdominal surgery.

\section{Methods $: \because$.}

\section{Inclusion criteria}

Randomized controlled trials where the IS was used in the pre and/or postoperative care aiming to prevent the incidence of PPCs in patients undergoing elective abdominal, cardiac or thoracic surgery were included in the present study. Narrative reviews, retrospective studies, non-controlled studies, personal communications, case reports, or studies that have assessed the use of the IS for training inspiratory musculature were excluded.

\section{Clinical outcomes}

Studies that have evaluated the following outcomes were considered eligible for inclusion in this study: pneumonia, atelectasis, pulmonary function, oxygenation and hospital stay length followed-up of for at least two days of postoperative care.

\section{Search strategy and study selection}

Searchers were conducted in the following databases: Medline, Embase, Web of Science, PEDro and Scopus and included studies published until up June $1^{\text {st }}, 2011$. The search terms used were: "incentive spirometry", "breathing exercise", "chest physical therapy", "respiratory therapy," "abdominal surgery", "cardiac surgery" and "thoracic surgery". A second search was performed scanning the references lists from the studies identified in the first search, in order to identify additional studies that were not identified in the first search. Studies published in English, Portuguese and Spanish languages were considered.

Two independent reviewers analyzed the abstracts and contents of all the studies identified in the electronic search. Both reviewers extracted the data and the agreement between them was verified. Discrepancies in data extraction were resolved by consensus. Then, studies that met all inclusion criteria were selected, using a standardized form ${ }^{19}$ which analyzed the following data:

Study assessment methods: hypothesis and study design, patient allocation procedures, length of treatment and follow-up period, primary outcome assessments, statistical analysis and representativeness of the sample as well as the presence of bias.

Participants: inclusion and exclusion criteria, age, gender, presence of comorbidities, type of surgery and other risk factors for PPCs.

Intervention: type, duration and frequency of the intervention, length and number of sessions.

Outcomes: definitions used in each study and statistical differences of the groups studied. 


\section{Studies quality criteria}

After inclusion and analysis of the retrieved studies, the reviewers assessed their quality using the PEDro (Physiotherapy Evidence Database) scale. The PEDro scores ranges from 0 to 10 according to the following criteria: eligibility and source of patients, random allocation of the participants, concealed allocation, baseline comparability between the groups with regards to the most important prognostic indicators, blinding of participants, blinding of the therapists who administered the therapy, blinding of the assessor who measured the outcomes, measurements of outcomes were obtained from more than $85 \%$ of the participants included in the study, intention-to-treat analysis, description of the betweengroup statistical comparisons, provides both point measures and measures of variability for the outcomes ${ }^{23}$.

\section{Results $: \because$.}

\section{Studies quality criteria}

\section{Studies selection}

From 250 selected studies, only 112 were considered to be included in this study. During the abstracts screening, 51 studies were excluded, being 21 reviews, 3 letters to the editors, 2 guidelines, 2 editorials, 1 congress summary, 2 questionnaires, 1 of pediatric field, 6 published in other language, 3 with nonsurgical patients, 3 studies used the IS for distinct goal than those considered for this review, and 7 that have not evaluated the outcomes of interest (Figure 1).

Thirty studies published between 1974 and 2011 were included in the analysis (Tables 1 and 2) being 14 studies evaluating the effect of IS in patients undergoing abdominal surgery $(n=2,153), 13$ studies in patients undergoing cardiac surgery $(n=1,081), 2$ studies in patients undergoing thoracic surgery ( $\mathrm{n}=99)$ and 1 study that included thoracic and abdominal surgery $(\mathrm{n}=37)$.

From the 14 studies included in the analysis of the effect of IS in patients undergoing abdominal surgery, 11 studies $(78 \%)$ had PEDro scores $\geq 5$ (Table 1). However, 12 studies $(86 \%)$ did not report the sample calculation, 5 studies $(36 \%)$ did not described the method of randomization, 5 studies (36\%) used co-interventions, 3 studies $(21 \%)$ had control group without intervention, 2 studies (15\%) did not

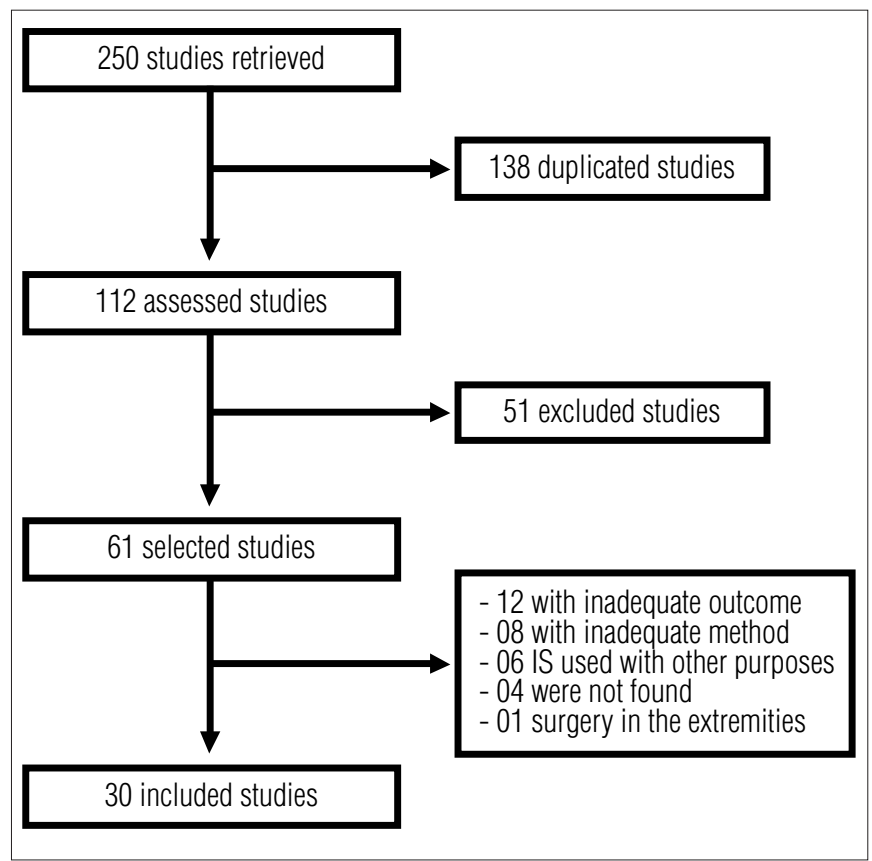

Figure 1. Flowchart of the included studies.

Table 1. Studies evaluating the effect of IS in abdominal surgery.

\begin{tabular}{|c|c|c|c|c|c|}
\hline Authors/year & $\mathrm{N}$ & Study design & Objective & Assessed Outcomes & PEDro \\
\hline Hall et al. ${ }^{24}$ & 876 & $P R$ & IS and RP on PPC in UAS & PPC & $8 / 10$ \\
\hline Hall et al. ${ }^{25}$ & 456 & PR & IS and DB on PPC in UAS & PPC & $8 / 10$ \\
\hline Cattano et al. ${ }^{26}$ & 37 & RCT & IS on LF and PPC in bariatric surgery & PPC and LF & $6 / 10$ \\
\hline Celli, Rodriguez and Snider ${ }^{27}$ & 172 & RCT & IS, IPPB and DB on PPC in UAS & $\mathrm{PPC}$ and $\mathrm{HS}$ & $6 / 10$ \\
\hline Kundra et al. ${ }^{28}$ & 50 & RCT & IS pre and postoperative on LF in laparoscopy & LF & $6 / 10$ \\
\hline O'Connor, Tattersall and Carter ${ }^{13}$ & 40 & RCT & IS on LF, PPC and HS in UAS & PPC, LF and HS & $6 / 10$ \\
\hline Ricksten et al..$^{29}$ & 43 & RCT & CPAP on PPC and PF in UAS & PPC, oxygenation and LF & $6 / 10$ \\
\hline Schwieger et al. ${ }^{30}$ & 40 & RCT & IS on PPC after UAS (ASA 1 and 2 patients) & PPC, oxygenation & $6 / 10$ \\
\hline Stock et al. ${ }^{31}$ & 65 & PR & IS, DB and CPAP on LF in UAS & PPC and LF & $6 / 10$ \\
\hline Craven et al. ${ }^{32}$ & 70 & RCT & IS on PPC in UAS & PPC & $5 / 10$ \\
\hline Lyager et al. ${ }^{33}$ & 94 & RCT & IS + SP in UAS & PPC and oxygenation & $5 / 10$ \\
\hline Dohi and Gold ${ }^{34}$ & 64 & PR & IS and IPPB on LF and PPC in UAS & PPC and LF & $4 / 10$ \\
\hline Jung et al. ${ }^{35}$ & 126 & RCT & IS, IPPB and resisted breathing in UAS & PPC & $4 / 10$ \\
\hline Minschaert et al. ${ }^{36}$ & 20 & RCT & IS on LF in UAS & $\mathrm{PPC}$ and LF & $3 / 10$ \\
\hline
\end{tabular}

$\mathrm{n}=$ sample size; $\mathrm{PEDro=Quality} \mathrm{score} \mathrm{assessed} \mathrm{by} \mathrm{database;} \mathrm{PR}=$ prospective and randomized study; IS=incentive spirometry; $\mathrm{RP}=$ respiratory physical therapy; $\mathrm{PPC}=$ postoperative pulmonary complications; UAS=upper abdominal surgery; RCT=randomized controlled trial; R=randomized; HS=hospital staying; SP=standard physical therapy; LF=lung function; IPPB=inspiratory positive pressure breathing; $\mathrm{DB}=$ deep breathing; CPAP=Continuous Positive Airway Pressure; $A$ ASA=American Society of Anesthesiology Scale. 
describe the definitions of the outcomes used and 2 studies $(15 \%)$ did not describe the statistical analysis used. The postoperative follow-up of the included studies varied from two to ten days.

From the 13 studies included in the analysis of the effect of IS in patients undergoing cardiac surgery, 8 studies $(61 \%)$ had PEDro scores $\geq 5$ (Table 2); 12 studies (93\%) did not report the sample calculation, 7 studies (54\%) did not describe the method of randomization, 7 studies (54\%) used co-intervention, 4 studies (31\%) did not describe the definitions of the outcomes used and only 1 study (8\%) had control group without intervention. The postoperative follow-up of the studies varied from two to 30 days. In thoracic surgery, two of the three studies evaluated had scores on PEDro scale $\geq 5$ (Table 2). In addition, two studies (67\%) studies did not report the sample calculation, not had control group without intervention and not used co-intervention. One study (33\%) did not describe the clinical outcomes used. The postoperative follow-up of the studies varied from three to 90 days.

\section{The effect of IS in the postoperative of abdominal surgery}

\section{PPC as an outcome}

Control group without treatment vs. IS: Three studies compared the effect of IS with a control group without intervention ${ }^{24,27,30}$, and no between-group differences were found.

Another intervention vs. IS: Eleven studies compared the effectiveness of IS with another intervention. In three of them ${ }^{32,34,35}$ the authors showed that the use of IS reduced the incidence of PPC compared with other physical therapy interventions; six studies ${ }^{13,24-26,30,33}$ showed no between group differences in the incidence of PCC between IS and other intervention; and two studies ${ }^{27,29}$ showed that IS failed to reduce the incidence of PPC when compared to exercises with positive pressure (CPAP or IPPB) (Table 3).

\section{Lung function as an outcome}

Control group without intervention vs. IS: Only one study compared the effect of IS with a control group ${ }^{30}$, and no between-groups changes in lung function were observed.

Another intervention vs. IS: One study ${ }^{36}$ compared the effect of IS with the "conventional physical therapy" and an early recovery of the tidal volume in patients who used IS was observed. One study ${ }^{31}$ compared the effect of IS with continuous positive airway pressure exercise (CPAP) and found that patients in the CPAP group presented an early increase in the lung volume compared to IS group. One study ${ }^{28}$ compared the use of IS in the preoperative period vs. the use of IS in the pre and postoperative periods and found that the use of IS in the postoperative period after laparoscopic surgery did not assist in the recovery of the vital capacity and forced expiratory volume in the first second (Table 3).

Six studies ${ }^{13,24-26,30,33}$ compared the use of IS with other interventions and found that IS had no effect in any of the outcomes investigated (Table 3). It should be emphasized that no study reported adverse effects from the use of IS.

\section{The effect of IS in the postoperative of cardiac surgery}

\section{PPC as an outcome}

Control group without intervention vs. IS: only one study compared the effects of IS with a control group without intervention ${ }^{41}$, and no between-group differences were observed.

Another intervention vs. IS: Nine studies evaluated the incidence of PPC $^{37,38,40,41,44,45,47,48,51}$. One study ${ }^{38}$ showed that the use of IS associated to exercises with positive pressure (EPAP) reduced the incidence of PPC in patients undergoing surgery for myocardial revascularization when compared with deep breathing (Table 4). One study ${ }^{48}$ showed that exercises with positive pressure (IPPB) reduced the incidence of PPC when compared to IS. Seven studies ${ }^{37,40,41,44,45,48}$ found no differences in the incidence of PPC when compared IS to another intervention.

\section{Lung function as an outcome}

Another intervention vs. IS: Eight studies evaluated the lung function as an outcome ${ }^{37,39,40,43-45,47,52}$, being two studies ${ }^{44,47}$, the IS improved the lung function when compared to other physical therapy interventions. One study ${ }^{39}$ showed that the IS did not restore the lung function after surgery when compared to the use of exercises with positive pressure. One study ${ }^{43}$ showed that patients who performed resisted breathing showed better recovery of lung volumes in comparison to IS (Table 4). In four studies $^{37,40,44,52}$, no differences in the improvement of lung function and in the oxygenation were observed when compared the IS to another intervention or to a control group without intervention (Table 4).

\section{The effects of IS in the postoperative of thoracic surgery}

Two studies ${ }^{46,50}$ evaluated the effect of IS compared to a control group without intervention. In one of those ${ }^{46}$, it was observed that patients who used the IS associated with inspiratory muscle training in the postoperative period presented an improvement in lung function when compared to a control group without intervention. In two studies ${ }^{42,50}$, the use of IS was not better than a control group without intervention for the outcomes early postoperative recovery of oxygenation, lung function or incidence of PPC (Table 4). 
Table 2. Studies evaluating the effect of IS in cardiac and thoracic surgery.

\begin{tabular}{|c|c|c|c|c|c|}
\hline Authors/year & $\mathrm{N}$ & Study design & Objective & Assessed Outcomes & PEDrc \\
\hline \multicolumn{6}{|l|}{ Cardiac Surgery } \\
\hline Crowe and Bradley ${ }^{37}$ & 185 & RCT & $\mathrm{IS}+\mathrm{DB}$ on $\mathrm{PPC}$ in $\mathrm{CABG}$ & PPC, oxygenation and HS & $6 / 10$ \\
\hline Haeffener et al. ${ }^{38}$ & 34 & RCT & IS + EPAP in CABG & MIP, LF, 6MWT and CR & $6 / 10$ \\
\hline Matte et al. ${ }^{39}$ & 90 & PR & IS e Positive Pressure on oxygenation, LF, DB in CABG & LF and oxygenation & $6 / 10$ \\
\hline Oikkonen et al. ${ }^{40}$ & 51 & PR & IS, IPPB and DB in CABG & PPC, LF and oxygenation & $6 / 10$ \\
\hline Yánez-Brage et al. ${ }^{41}$ & 159 & RCT & DB pre on PPC in CABG & PPC and LF & $6 / 10$ \\
\hline Dias et al. ${ }^{43}$ & 35 & RCT & IS and breath stacking on LF in CS & LF & $5 / 10$ \\
\hline Jenkins et al. ${ }^{44}$ & 110 & PR & IS and DB on LF and PPC in CABG & PPC and LF & $5 / 10$ \\
\hline Stock et al. ${ }^{45}$ & 38 & $P R$ & IS, CPAP and DB on LF and oxygenation in CS & PPC and LF & $5 / 10$ \\
\hline Gale and Sanders ${ }^{47}$ & 109 & PR & IS and IPPB on LF and PPC in CABG & PPC, LF and oxygenation & $4 / 10$ \\
\hline Iverson et al. ${ }^{48}$ & 145 & PR & IS, IPPB and RB on PPC in CS & PPC & $4 / 10$ \\
\hline Romanini et al. ${ }^{49}$ & 40 & RCT & IS and IPPB in CABG & MV, oxygenation, MIP and MEP & $4 / 10$ \\
\hline Dull and Dull|51 & 49 & RCT & IS, DB and mobilization in CABG & PPC and LF & $3 / 10$ \\
\hline Renault et al. .52 $^{2}$ & 36 & PR & IS and DB on LF, MIP and MEP and oxygenation in CABG & LF, MIP, MEP and oxygenation & $2 / 10$ \\
\hline \multicolumn{6}{|l|}{ Thoracic Surgery } \\
\hline Gosselink et al. ${ }^{42}$ & 67 & RCT & $\mathrm{IS}+\mathrm{DB}$ on PPC in TS & PPC and $\mathrm{HS}$ & $6 / 10$ \\
\hline Vilaplana et al. 46 & 37 & RCT & IS on LF, PPC and oxygenation in UAS and TS & PPC, LF, oxygenation and HS & $5 / 10$ \\
\hline Weiner et al..$^{50}$ & 32 & RCT & IS + resisted breathing on LF in TS & LF & $4 / 10$ \\
\hline
\end{tabular}

n=sample size; PEDro=Quality score assessed by database; RCT=randomized controlled trial; IS=incentive spirometry; DB=deep breathing; PPC=postoperative pulmonary complications; $\mathrm{CABG}=$ =ardiopulmonary bypass; $\mathrm{HS}=$ hospital staying; EPAP=Expiratory positive airway pressure; MIP and MEP=maximum inspiratory and expiratory pressure; LF=lung function; 6MWT=6 min walking test; $C R=C h e s t$ radiographic; IPPB=inspiratory positive pressure breathing; RB=resisted breathing; CS=cardiac surgery; UAS=upper abdominal surgery; MV=time of mechanical ventilation; CPAP=Continuous Positive Airway Pressure; TS=thoracic surgery; RB=resisted breathing.

Table 3. Characteristics and results of the studies evaluating the effect of IS in abdominal surgery.

\begin{tabular}{|c|c|c|c|c|c|}
\hline Authors & Control & Other intervention & IS & IS + co intervention & Results \\
\hline Hall et al. ${ }^{24}$ & $\begin{array}{l}\text { According to the physical } \\
\text { therapist (n=445) }\end{array}$ & & IS $5 \mathrm{~min} / \mathrm{h}(\mathrm{n}=431)$ & & Similar: PPC and HS \\
\hline Schwieger et al. ${ }^{30}$ & No treatment $(n=20)$ & & $\begin{array}{l}\text { IS } 5 \min / \mathrm{h}, 12 \mathrm{x} / \text { day } \\
(\mathrm{n}=20)\end{array}$ & & $\begin{array}{l}\text { Similar: PPC, oxygena- } \\
\text { tion and LF }\end{array}$ \\
\hline $\begin{array}{l}\text { Celli, Rodriguez and } \\
\text { Snider27 }\end{array}$ & No treatment $(n=44)$ & $\begin{array}{l}\text { IPPB 15min }(n=45) \\
\text { DB 10x }(n=41)\end{array}$ & IS 10x (n=42) & & PPC on IPPB $<$ IS \\
\hline Cattano et al. ${ }^{26}$ & & IS $3 x, 1 x /$ day $(n=19)$ & IS $10 x, 5 x /$ day (n=18) & & Similar PPC \\
\hline Kundra et al. ${ }^{28}$ & & IS 15x P0 (n=25) & & $\begin{array}{c}\text { IS } 15 x / 15 \text { min Pre and } \\
\text { PO (n=25) }\end{array}$ & LF on IS Pre > IS PO \\
\hline Hall et al. ${ }^{25}$ & & $\begin{array}{c}\text { DB LR 10x/h }(n=76) \\
\text { DB HR } 10 R P+S P / h \\
(n=149)\end{array}$ & $\begin{array}{l}\text { IS LR 10x/h (n=79) } \\
\text { IS HR 10x/h ( } n=152)\end{array}$ & & Similar PPC \\
\hline $\begin{array}{l}\text { O'Connor, Tattersall and } \\
\text { Carter }^{13}\end{array}$ & & $\operatorname{RP}(n=20)$ & & IS $3 x / h+R P(n=20)$ & Similar: PPC and LF \\
\hline Ricksten et al..$^{29}$ & & IS 30x/h + SP (n=15) & & $\begin{array}{l}\text { CPAP } 30 / h+R P(n=13) ; \\
\text { PEP 30/h + RP }(n=15)\end{array}$ & $\begin{array}{l}\text { Similar: oxygenation and } \\
\text { LF, and } \uparrow \text { PPC on IS }\end{array}$ \\
\hline Stock et al. ${ }^{31}$ & & $\begin{array}{c}\mathrm{DB}+\text { Huffing } 5 \mathrm{x} / 30 \mathrm{~min} \\
(\mathrm{n}=20) \\
\text { CPAP } 5 x / 30 \mathrm{~min}(\mathrm{n}=23)\end{array}$ & IS 15min (n=22) & & $\begin{array}{c}\downarrow P P C \text { and } \uparrow \text { LF on } \\
\text { CPAP }\end{array}$ \\
\hline Minschaert et al..$^{36}$ & & $\begin{array}{c}\mathrm{PD}+\mathrm{TP}+\mathrm{DB}+\text { cough+walking } \\
(\mathrm{n}=9)\end{array}$ & IS 6x/h (n=11) & & $I S \uparrow L F$ \\
\hline Jung et al..$^{35}$ & & $\begin{array}{l}\text { Walking } 15 \min +\text { IPPB } \\
15 \min 4 x / \text { day }(n=36)\end{array}$ & & $\begin{array}{l}\text { Walking 15min + IS } \\
15 \mathrm{~min}, 4 \mathrm{x} / \text { day }(\mathrm{n}=36)\end{array}$ & $\begin{array}{l}\downarrow P P C \text { on IS in major } \\
\text { surgeries }\end{array}$ \\
\hline Dohi and Gold ${ }^{34}$ & & IPPB $15 \min (n=30)$ & IS 15min (n=34) & & $\downarrow$ PPC on IS $(\mathrm{p}=0.05)$ \\
\hline Craven et al. ${ }^{32}$ & & SP $2 x /$ day $(n=35)$ & IS 10x/h (n=35) & & $\downarrow P P C$ on IS \\
\hline Lyager et al. ${ }^{33}$ & & $\begin{array}{c}\text { Orientation of Cough + DB } \\
(\mathrm{n}=43)\end{array}$ & & $\begin{array}{l}\text { Orientation of IS } 4 x / h \\
(n=51)\end{array}$ & $\begin{array}{c}\text { Similar: PPC, oxygena- } \\
\text { tion and HS }\end{array}$ \\
\hline
\end{tabular}

IS=incentive spirometry; PPC=postoperative pulmonary complications; HS=hospital staying; LF=lung function; IPPB=inspiratory positive pressure breathing; DB=deep breathing; $\mathrm{PO}=$ =postoperative; Pre=pre-operative; $\mathrm{LR}=$ low risk; HR=high risk; RP=respiratory physical therapy; PEP=positive expiratory pressure; CPAP=Continuous Positive Airway Pressure; $\mathrm{SP}=$ standard physical therapy; $\mathrm{TP}=$ thoracic percussion; $\mathrm{PD}=$ postural drainage; $\mathrm{x} / \mathrm{h}=$ number of repetitions per hour; $\mathrm{x} / \mathrm{day}=$ number of times per day. 
Table 4. Characteristics and results of the studies evaluating the effect of IS in cardiac and thoracic surgery.

\begin{tabular}{|c|c|c|c|c|c|}
\hline Authors & Control & Other intervention & IS & IS + co intervention & Results \\
\hline \multicolumn{6}{|l|}{ Thoracic Surgery } \\
\hline Weiner et al. ${ }^{50}$ & No treatment $(n=15)$ & & & $\begin{array}{l}\text { IS 30x + RB 30min/1h } \\
\text { (Pre+P0) }(n=17)\end{array}$ & $\uparrow \mathrm{LF}$ on IS + RB \\
\hline Vilaplana et al. ${ }^{46}$ & No treatment $(n=19)$ & & IS $5 \mathrm{~min} / 1 \mathrm{~h}(\mathrm{n}=18)$ & & $\begin{array}{c}\text { Similar: LF, oxygenation } \\
\text { and PPC }\end{array}$ \\
\hline Gosselink et al. ${ }^{42}$ & & $\begin{array}{c}\text { Orientation 5-10 } \\
\text { IMT+FE+ } \\
\text { cough } 2 x / 1 \mathrm{~h}(\mathrm{n}=35)\end{array}$ & & $\begin{array}{l}\text { Orientation } 10-20 \\
I S+F E+A C / 1 h\end{array}$ & Similar: PPC and HS \\
\hline \multicolumn{6}{|l|}{ Cardiac Surgery } \\
\hline Yánez-Brage et al. ${ }^{41}$ & No treatment $(n=104)$ & & IS 30x/1h (n=159) & & Similar PPC \\
\hline Dias et al. ${ }^{43}$ & & $\begin{array}{l}\text { Orientation pre }(\mathrm{n}=11) \\
\mathrm{RB}+\text { orientation }(\mathrm{n}=12)\end{array}$ & & IS + orientation ( $n=12)$ & $\uparrow \mathrm{LF}$ on $\mathrm{RB}$ \\
\hline Renault et al..$^{52}$ & & $\begin{array}{c}\mathrm{DB}+\mathrm{AC}+\mathrm{EM} 30 \mathrm{x} / \mathrm{day} \\
(\mathrm{n}=18)\end{array}$ & & IS+AC+EM 30x (n=18) & $\begin{array}{c}\text { Similar: LF, MP and } \\
\text { oxygenation }\end{array}$ \\
\hline Haeffener et al..$^{38}$ & & Orientation + DB (n=17) & & $\begin{array}{l}\text { IS + EPAP 18x, 2x/day } \\
(n=17)\end{array}$ & $\begin{array}{c}\text { MIP, 6MWT, PPC and HS } \\
\downarrow \text { on IS+EPAP }\end{array}$ \\
\hline Romanini et al. ${ }^{49}$ & & IPPB 20 min/day (n=20) & IS $20 \min (n=20)$ & & $\uparrow \mathrm{MP}$ on IS \\
\hline Matte et al. ${ }^{39}$ & & $\begin{array}{c}C P A P+S P(n=31) \\
\text { Bilevel }+S P 1 h / 3 h \\
\quad(n=31)\end{array}$ & & IS $20 x+S P / 2 h(n=28)$ & LF and oxygenation $\downarrow$ IS \\
\hline Crowe and Bradley ${ }^{37}$ & & $\mathrm{SP}(\mathrm{n}=95)$ & & $I S+S P / 1 h(n=32)$ & Similar: LF, PPC and HS \\
\hline Oikkonen et al. ${ }^{40}$ & & IPPB 10x 4x/day (n=26) & & IS + RP 5x,/2h (n=25) & $\begin{array}{l}\text { Similar: LF, oxygenation } \\
\text { and PPC }\end{array}$ \\
\hline Jenkins et al..$^{44}$ & & $\begin{array}{l}\text { EM (n=37); RP + TP } \\
(n=38) 30-50 x / h\end{array}$ & IS 30-50x/1h (=35) & & Similar: PPC, LF and HS \\
\hline Stock et al. ${ }^{45}$ & & $\begin{array}{c}\text { IMT } 4-5 \mathrm{x}+\mathrm{AC} / 2 \mathrm{~h} \\
(\mathrm{n}=13) \\
\text { CPAP } 2-3 \mathrm{x} / 5 \min (\mathrm{n}=13)\end{array}$ & IS $5 x / 2 h(n=12)$ & & $\begin{array}{l}\text { Similar PPC and } \uparrow \mathrm{LF} \\
\quad \text { on IS }\end{array}$ \\
\hline Dull and Dull|51 & & $\begin{array}{c}\text { EM + AC } 2 \text { x/day }(n=16) \\
\text { IMT + EM 10x, 4x/day } \\
(n=17)\end{array}$ & & $\begin{array}{l}\text { IS } 10 x+E M \text { 4x/day } \\
(n=16)\end{array}$ & Similar PPC \\
\hline Gale and Sanders ${ }^{47}$ & & IPPB 20x/4h (n=57) & IS 10-20min/4h (n=52) & & $\begin{array}{c}\text { Similar: } \uparrow \text { LF on IS, PPC } \\
\text { and oxygenation }\end{array}$ \\
\hline Iverson et al..$^{48}$ & & $\begin{array}{c}\text { IPPB (n=42) 15min; RB } \\
(n=45) 3-5 x / 3 \mathrm{~h}\end{array}$ & IS 3-5x/3h (n=58) & & $\downarrow P C P$ on $R B$ \\
\hline
\end{tabular}

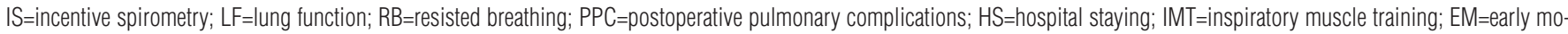
bilization; IPPB=inspiratory positive pressure breathing; $\mathrm{FE}=$ forced expiration; $\mathrm{DB}=$ deep breathing; $\mathrm{AC}=$ assisted cough; $\mathrm{TP}=$ thoracic percussion; $\mathrm{PO}=$ postoperative; Pre=pre-operative; $\mathrm{MP}=$ maximum respiratory pressures; $\mathrm{MIP}=$ maximum inspiratory pressure; $6 \mathrm{MWT}=6$ minutes walking test; $\mathrm{RP}=$ respiratory physical therapy; $\mathrm{CPAP}=\mathrm{Continuous} \mathrm{Positive} \mathrm{Airway} \mathrm{Pressure;}$ $\mathrm{SP}=$ standard physical therapy; $\mathrm{x} / \mathrm{h}=$ number of repetitions per hour; $\mathrm{x} /$ day=number of times per day; $\mathrm{EPAP}=$ Expiratory positive airway pressure.

\section{Discussion $\because:$.}

The results of the eligible studies showed that there is no evidence to support the use of IS in pre and/or post-operative care of patients undergoing abdominal, cardiac or thoracic surgery. In this systematic review, the inclusion of studies and their analysis were performed through a comprehensive search strategy and independent assessment performed by two reviewers with regards to the methodological quality of the retrieved studies in order to verify the evidence to support the wide use of IS in clinical practice.
Most of the included studies have evaluated the effect of IS associated with another intervention, and the patients follow-up period was short which limits the analysis of the isolated effect of IS. Another finding of this review was the progressive reduction of the published studies designed to evaluate the effect of IS in the postoperative period. In addition, these studies also presented a small number of included patients and the sample size calculation was not presented.

Studies evaluating the effect of IS presented the same methodological quality score (PEDroミ5) independently of 
the surgery evaluated. It was also observed that there was no improvement in the methodological quality of studies over time. Nine (30\%) included studies (three in abdominal ${ }^{34-36}$, five in $\operatorname{cardiac}^{47-52}$ and one $\mathrm{e}^{50}$ in thoracic surgery) presented PEDro scores below 5, and six of them showed that the use of IS favors the early recovery of lung function or the prevention of PPC. The methodological flaws found in most studies were the lack of a sample size calculation, problems in experimental design and inadequate method of randomization, and this may have generated bias in the interpretation of the results obtained by the treatment with the IS.

Analyzing only the studies ${ }^{24-36}$ that evaluated the effect of IS in patients undergoing abdominal surgery, showed that this technique did not demonstrate to be beneficial in relation to other physical therapy interventions in the prevention of PPC. Some factors can be analyzed to justify these findings: first, the lack of consensus among physical therapists with regards to the gold standard intervention in the postoperative period, including the appropriate number of repetitions, duration of therapy and other postoperative treatments that may influence the results found. In the absence of a gold standard intervention, the studies should perhaps prioritize the experimental design that included a control group without intervention to better estimate the effects of IS, however only three studies were found with this purpose $e^{24,27,30}$. Second, the IS continues to be widely used in clinical practice and recommended as prophylaxis of PPC in the recent pre-operative evaluation consensus ${ }^{1,15}$. However, since the last conducted systematic review ${ }^{19}$, few studies were published, a fact that seems contradictory, since IS remains widely used in postoperative of abdominal surgery care even without proven evidence. Third, a large variability in the population included in the studies that evaluated the effect of IS was found, being in some studies, there were the inclusion of patients with low risk of developing PPC, few associated comorbidities, low surgical duration (less than 210 minutes) and patients underwent laparoscopic surgery (very low risk). This allows us to infer that the absence of the effect may have occurred because the use of the IS may not be necessary for all patients, but only for those at high risk and whom are most likely to develop PPC in the postoperative period. Finally, it is important to remember that there are two types of incentive spirometers, i.e. flow incentive and volume incentive, and little is known about the differences between them. Some studies ${ }^{12,33,47}$ included in this review used a specific type of incentive spirometer (the Bartlet), which is currently considered outdated equipment and it is no longer commercially available.

With regards to cardiac surgery, no sufficient evidence for the use of IS was found. Since the last systematic review on the prevention of PPC in cardiac surgery ${ }^{21}$, five studies were published to evaluate the effectiveness of IS. From these studies, only one ${ }^{41}$ included a control group without intervention, and no between-group difference was found with regards to the incidence of PPC, which makes definitive conclusions about the effect of IS in these patients impossible. Most of the studies that compare the IS with another physical therapy intervention perform the exercises with a positive pressure equipment such as CPAP and Bilevel, and evaluate as an outcome the reduction of PPC or the improvement of postoperative lung function. These studies showed that patients who performed exercises with positive pressure presented a faster recovery of lung function in the postoperative period when compared to IS, however this improvement, although statistically significant, cannot be considered clinically relevant, since PPC incidence had not been evaluated. Due to the absence of a control group (without intervention), it is not possible to ensure that both the use of IS and the use of positive pressure exercises presents an improvement in relation to the absence of such therapies. Another factor that hampers the understanding of the effect of IS is the large variability found in studies regarding how to use the equipment with positive pressure. The results regarding the IS effect in patients undergoing thoracic surgery are inconclusive and, since the last systematic review, no study was been published that supports the use of IS in the postoperative period of these surgeries.

This systematic review presents some methodological limitations, such as the inclusion of only studies published in English, Portuguese and Spanish languages. Furthermore, it was not possible to contact the authors of the studies whose data were not included in the published manuscript, however, it is believed that such data were not crucial for our analysis.

\section{Conclusion $: \because$.}

No evidence was found that support the use of IS in the management of surgical patients, and there is an urgent need for studies with adequate methodological designs to clarify the effect and to justify the use of this technique. Nevertheless, the use of IS is still widely used among health professionals.

\section{Acknowledgments $: \because$}

To the Conselho Nacional de Desenvolvimento Cientifico e Tecnológico (CNPq), for the financial support. 
1. Smetana GW. Postoperative pulmonary complications: an update on risk assessment and reduction. Cleve Clin J Med. 2009;76 Suppl 4:S60-5.

2. Serejo LG, da Silva-Júnior FP, Bastos JP, de Bruin GS, Mota RM, de Bruin PF. Risk factors for pulmonary complications after emergency abdominal surgery. Respir Med. 2007;101(4):808-13.

3. Waissman C. Pulmonary complications after cardiac surgery. Semin Cardiothorac Vasc Anesth. 2004;8(3):185-211

4. CanetJ, GallartL, Gomar C, Paluzie G, Vallès J, Castillo J, etal. Prediction of postoperative pulmonary complications in a population-based surgical cohort. Anesthesiology. 2010;113(6):1338-50.

5. Rudra A, Sudipta D. Postoperative pulmonary complications. Indian J Anaesth. 2006;50(2):89-98.

6. Rock P, Rich PB. Postoperative pulmonary complications. Curr Opin Anaesthesiol. 2003;16(2):123-31.

7. Joehl RJ. Preoperative evaluation: pulmonary, cardiac, renal dysfunction and comorbidities. Surg Clin North Am. 2005;85(6):1061-73.

8. Lawrence VA, Hazuda HP, Cornell JE, Pederson T, Bradshaw PT, Mulrow CD, et al. Functional independence after major abdominal surgery in the elderly. J Am Coll Surg. 2004;199(5):762-72.

9. Dimick JB, Chen SL, Taheri PA, Henderson WG, Khuri SF, Campbell DA Jr. Hospital costs associated with surgical complications: a report from the private-sector National Surgical Quality Improvement Program. J Am Coll Surg. 2004;199(4):531-7.

10. Jaber S, Delay JM, Chanques G, Sebbane M, Jacquet E, Souche B, et al. Outcomes of patients with acute respiratory failure after abdominal surgery treated with noninvasive positive pressure ventilation. Chest. 2005;128(4):2688-95

11. Warner DO. Preventing postoperative pulmonary complications: the role of the anesthesiologist. Anesthesiology. 2000;92(5):1467-72.

12. Bartlett RH, Gazzaniga $A B$, Geraghty TR. Respiratory maneuvers to prevent postoperative pulmonary complications. A critical review. JAMA. 1973;224(7):1017-21.

13. O'Connor M, Tattersall MP, Carter JA. An evaluation of the incentive spirometer to improve lung function after cholecystectomy. Anaesthesia. 1988;43(9):785-7.

14. Duggan M, Kavanagh BP. Perioperative modifications of respiratory function. Best Pract Res Clin Anaesthesiol. 2010;24(2):145-55

15. Arozullah AM, Conde MV, Lawrence VA. Preoperative evaluation for postoperative pulmonary complications. Med Clin North Am. 2003;87(1):153-73.

16. Westerdahl E, Lindmark B, Eriksson T, Friberg 0, Hedenstierna G, Tenling A. Deep-breathing exercises reduce atelectasis and improve pulmonary function after coronary artery bypass surgery. Chest. 2005;128(5):3482-8.

17. O'Donohue WJ Jr. Prevention and treatment of postoperative atelectasis. Can it and will it be adequately studied? Chest. 1985;87(1):1-2.

18. AARC (American Association for Respiratory Care) clinical practice guideline. Incentive spirometry. Respir Care. 1991;36(12):1402-5

19. Overend TJ, Anderson CM, Lucy SD, Bhatia C, Jonsson BI, Timmermans C. The effect of incentive spirometry on postoperative pulmonary complications: a systematic review. Chest. 2001;120(3):971-8.

20. Guimarães MM, El Dib R, Smith AF, Matos D. Incentive spirometry for prevention of postoperative pulmonary complications in upper abdominal surgery. Cochrane Database Syst Rev. 2009;(3):CD006058.

21. Pasquina $P$, Tramèr MR, Walder B. Prophylactic respiratory physiotherapy after cardiac surgery: systematic review. BMJ. 2003;327(7428):1379.

22. Agostini $P$, Calvert $R$, Subramanian $H$, Naidu B. Is incentive spirometry effective following thoracic surgery? Interact Cardiovasc Thorac Surg. 2008;7(2):297-300.

23. Maher CG, Sherrington C, Herbert RD, Moseley AM, Elkins M. Reliability of the PEDro scale for rating quality of randomized controlled trials. Phys Ther. 2003;83(8):713-21.

24. HallJC, TaralaR, Harris J, Tapper J, Christiansen K. Incentive spirometry versus routine chest physiotherapy for prevention of pulmonary complications after abdominal surgery. Lancet. 1991;337(8747):953-6.

25. Hall JC, Tarala RA, Tapper J, Hall JL. Prevention of respiratory complications after abdominal surgery: a randomized clinical trial. BMJ. 1996;312(7024):148-53.

26. Cattano D, Altamirano A, Vannucci A, Melnikov V, Cone C, Hagberg CA. Preoperative use of incentive spirometry does not affect postoperative lung function in bariatric surgery. Transl Res. 2010;156(5):265-72

27. Celli BR, Rodriguez KS, Snider GL. A controlled trial of intermittent positive pressure breathing, incentive spirometry, and deep breathing exercises in preventing pulmonary complications after abdominal surgery. Am Rev Respir Dis. 1984;130(1):12-5.
28. Kundra P, Vitheeswaran M, Nagappa M. Sistla S. Effect of preoperative and postoperative incentive spirometry on lung functions after laparoscopic cholecystectomy. Surg Laparosc Endosc Percutan Tech. 2010;20(3):170-2.

29. Ricksten SE, Bengtsson A, Soderberg C, Thorden M, Kvist H. Effects of periodic positive airway pressure by mask on postoperative pulmonary function. Chest. 1986;89(6):774-81.

30. Schwieger I, Gamulin Z, Forster A, Meyer P, Gemperle M, Suter PM. Absence of benefit of incentive spirometry in low-risk patients undergoing elective cholecystectomy. A controlled randomized study. Chest. 1986;89(5):652-6.

31. Stock MC, Downs JB, Gauer PK, Alster JM, Imrey PB. Prevention of postoperative pulmonary complications with CPAP, incentive spirometry, and conservative therapy. Chest. 1985;87(2):151-7.

32. Craven JL, Evans GA, Davenport PJ, Williams RHP. The evaluation of the incentive spirometer in the management of postoperative pulmonary complications. Br J Surg. 1974;61(10):793-7.

33. Lyager S, Wernberg M, Rajani N, Bøggild-Madsen B, Nielsen L, Nielsen HC, et al. Can postoperative pulmonary conditions be improved by treatment with the Bartlett-Edwards incentive spirometer after upper abdominal surgery? Acta Anaesthesiol Scand. 1979;23(4):312-9.

34. Dohi S, Gold Ml. Comparison of two methods of postoperative respiratory care. Chest 1978;73(5):592-5

35. Jung R, Wight J, Nusser R, Rosoff L. Comparison of three methods of respiratory care following upper abdominal surgery. Chest. 1980;78(1):31-5.

36. Minschaert M, Vincent JL, Ros AM, Kahn RJ. Influence of incentive spirometry on pulmonary volumes after laparotomy. Acta Anaesthesiol Belg. 1982:33(3):203-9.

37. Crowe JM, Bradley CA. The effectiveness of incentive spirometry with physical therapy for highrisk patients after coronary artery bypass surgery. Phys Ther. 1997;77(3):260-8.

38. Haeffener MP, Ferreira GM, Barreto SS, Arena R, Dall'Ago P. Incentive spirometry with expiratory positive airway pressure reduces pulmonary complications, improves pulmonary function and 6-minute walk distance in patients undergoing coronary artery bypass graft surgery. Am Heart J. 2008;156(6):901-8.

39. Matte P, Jacquet L, Van Dyck M, Goenen M. Effects of conventional physiotherapy, continuous positive airway pressure and non-invasive ventilatory support with bilevel positive airway pressure after coronary artery bypass grafting. Acta Anaesthesiol Scand. 2000;44(1):75-81.

40. Oikkonen M, Karjalainen K, Kähärä V, Kuosa R, Schavikin L. Comparison of incentive spirometry and intermittent positive pressure breathing after coronary artery bypass graft. Chest. 1991;99(1):60-5

41. Yánez-Brage I, Pita-Fernández S, Juffé-Stein A, Martínez-González U, Pértega-Díaz S, MauleónGarcía A. Respiratory physiotherapy and incidence of pulmonary complications in off-pump coronary artery bypass graft surgery: an observational follow-up study. BMC Pulm Med. 2009;9:36.

42. Gosselink R, Schrever K, Cops P, Witvrouwen H, De Leyn P, Troosters T, et al. Incentive spirometry does not enhance recovery after thoracic surgery. Crit Care Med. 2000;28(3):679-83.

43. Dias CM, Vieira Rde 0, Oliveira JF, Lopes AJ, de Menezes SL, Guimarães FS. Three physiotherapy protocols: effects on pulmonary volumes after cardiac surgery. J Bras Pneumol. 2011;37(1):54-60.

44. Jenkins SC, Soutar SA, Loukota JM, Johnson LC, Moxham J. Physiotherapy after coronary artery surgery: are breathing exercises necessary? Thorax. 1989;44(8):634-9.

45. Stock MC, Downs JB, Cooper RB, Lebenson IM, Cleveland J, Weaver DE, et al. Comparison of continuous positive airway pressure, incentive spirometry, and conservative therapy after cardiac operations. Crit Care Med. 1984;12(11):969-72.

46. Vilaplana J, Sabaté A, Ramon R, Gasolibe V, Villalonga R. Ineffectiveness of incentive spirometry as coadjuvant of conventional physiotherapy for the prevention of postoperative respiratory complications after thoracic and esophageal surgery. Rev Esp Anestesiol Reanim. 1990;37(6):321-5.

47. Gale GD, Sanders DE. Incentive spirometry: its value after cardiac surgery. Can Anesth Soc J. 1980;27(5):475-80.

48. Iverson LI, Ecker RR, Fox HE, May IA. A comparative study of IPPB, the incentive spirometer, and blow bottles: the prevention of atelectasis following cardiac surgery. Ann Thorac Surg. 1978;25(3):197-200

49. Romanini W, Muller AP, Carvalho KA, Olandoski M, Faria-Neto JR, Mendes FL, et al. The effects of intermittent positive pressure and incentive spirometry in the postoperative of myocardia revascularization. Arq Bras Cardiol. 2007;89(2):94-9.

50. Weiner P, Man A, Weiner M, Rabner M, Waizman J, Magadle R, et al. The effect of incentive spirometry and inspiratory muscle training on pulmonary function after lung resection. J Thorac Cardiovasc Surg. 1997;113(3):552-7.

51. Dull JL, Dull WL. Are maximal inspiratory breathing exercises or incentive spirometry better than early mobilization after cardiopulmonary bypass? Phys Ther. 1983;63(5):655-9.

52. Renault JA, Costa-Val R, Rosseti MB, Houri Neto M. Comparison between deep breathing exercises and incentive spirometry after CABG surgery. Rev Bras Cir Cardiovasc. 2009:24(2):165-72. 